\title{
ОДНОЧАСТОТНЫЕ ЛАЗЕРЫ ОТ КОМПАНИИ Thorlabs
}

\begin{abstract}
Перестраиваемые одночастотные лазерные системы широко используются в различных технических системах самого разного применения. В мире диодных лазеров в настоящее время существует четыре конфигурации лазеров для получения одночастотного излучения: лазер с внешним резонатором (ECL), с распределенной обратной связью (DFL), с объемной голографической решеткой (VHG) и с распределенным брэгговским отражателем (DBR). Принцип работы всех четырех типов лазеров основан на использовании решетки, обеспечивающей обратную связь. Однако каждый тип лазера имеет разную конфигурацию такой решетки. Она влияет на эксплуатационные характеристики лазера: выходную мощность, диапазон перестройки и коэффициент подавления боковой моды (SMSR). Обсудим несколько главных отличий между данными типами одночастотных диодных лазеров.
\end{abstract}

\section{ЛАЗЕРЫ С ВНЕШНИМ РЕЗОНАТОРОМ (ЕСL)}

Лазер с внешним резонатором обладает универсальной конфигурацией, которая подходит для большинства стандартных диодных лазеров без оптоволоконного вывода. Это означает, что ECL можно использовать на различных длинах волн в зависимости от внутреннего элемента усиления лазерного диода. Линза-коллиматор на выходе диода направляет пучок на решетку (рис. 1). Решетка обеспечивает оптическую обратную связь и используется для выбора стабилизированной выходной длины волны. При правильной оптической конструкции внешний резонатор позволяет генерировать только одну продольную моду, обеспечивая одночастотный выход лазера с высоким коэффициентом подавления боковой моды (SMSR > 45 дБ).

Одно из главных достоинств ECL-лазера - это обеспечение относительно длинным резонатором чрезвычайно узкой ширины линий (<1 мГц). Кроме того, поскольку такая система может включать в себя множество лазерных диодов, она остается одной из немногих конфигураций, которые могут обеспечить излучение с узкой шириной линии в синем или красном спектральных диапазонах. Лазеры с внешним резонатором могут иметь широкий диапазон перестройки (>100 нм), но часто склонны к скачкам мод, которые сильно зависят от механической конструкции лазера, а также качества просветляющего покрытия.

\section{ЛАЗЕРЫ С РАСПРЕДЕЛЕННОЙ ОБРАТНОЙ СВЯЗЬЮ (DFB)}

Лазер с распределенной обратной связью (DFB) обладает решеткой внутри самой диодной структуры (рис. 2). Эта ребристая периодическая структура в сочетании с близко расположенной активной областью выступает в качестве отражателя Брэгга, отбирая одну продольную моду в качестве генерируемой. Если активная область имеет достаточное усиление на частотах, близких к частоте Брэгга, то нет необходимости в отражателе на конце активной среды, так как оптическая обратная связь и селекция мод осуществляется с помощью зеркала Брэгга.

Благодаря встроенной системе селекции мод DFB-лазер может работать в одночастотном режиме в широком диапазоне температур и значений тока. Для облегчения выбора режима и повышения выхода изготовления в DFB-лазерах часто используется секция фазового сдвига в структуре диода. Для повышения производительности и содействия селекции мод DFB-лазеры часто оснащены элементом для внесения фазового сдвига внутри диодной структуры.

Длина волны генерации для DFB-лазера приблизительно равна длине волны Брэгга: $\lambda=2 n_{\text {eff }} \times \Lambda$, где $\lambda$ - длина волны, $n_{\text {eff }}$ - эффективный показатель преломления, $\Lambda$ - период решетки. При изменении эффективного показателя преломления изменяется длина волны генерации. Это достигается за счет температуры и тока перестройки DFB-лазера.

Лазер с внешним резонатором (ECL)

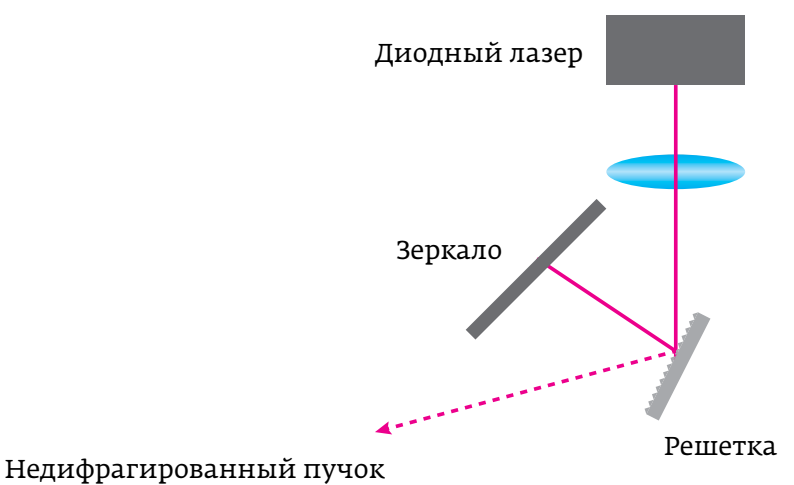

Puc. 1. Решетка в ECL-лазерах расположена за предепами активной среды 


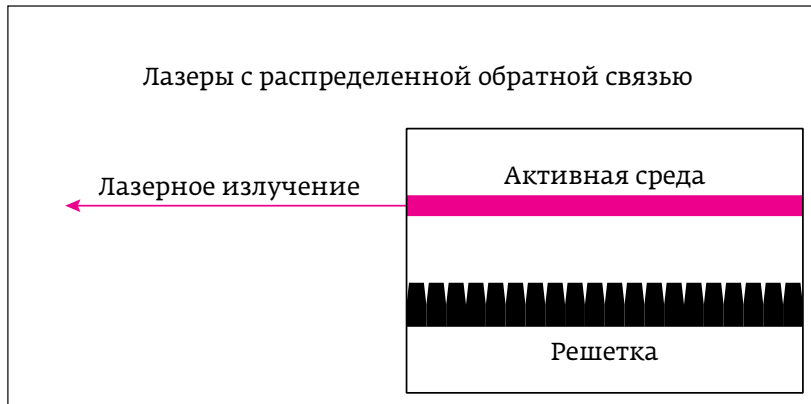

Puс. 2. Брэгговский отражатель вдоль всей активной среды DFB-лазера

Лазеры с распределенной обратной связью имеют относительно узкий диапазон перестройки: -2 нм на 850 нм, 4 нм на 1550 нм, и минимум 2 см$^{-1}$ в среднем ИК -диапазоне (4,54-9,60 мкм). Тем не менее в указанных диапазонах перестройки DFB-лазер может работать в одночастотном режиме, что означает непрерывный диапазон перестройки без скачков мод. Благодаря этой особенности, DFB-лазеры стали популярным выбором для различных применений, таких как телекоммуникации и детекторы. Так как длина резонатора лазера довольно короткая, ширина линий, как правило, составляет от 1 МГц до 10 МГц.
Кроме того, тесная связь между структурой решетки и активной средой приводит к более низким значениям максимальной выходной мощности излучения по сравнению с ECL-лазерами.

\section{ЛАЗЕРЫ С ОБЪЕМНОЙ ГОЛОГРАФИЧЕСКОЙ РЕШЕТКОЙ (VHG)}

В лазерах с объемной голографической решеткой (VHG) также используется отражатель Брегга, но в данном случае пропускающая дифракционная решетка расположена перед выходным окном лазерного диода (рис. 3). Так как решетка не является частью конструкции лазерного диода, она может быть термически отделена от лазерного диода, что улучшает стабильность длины волны излучения системы. Как правило, решетка состоит из фоторефрактивного материала (стекло), который обладает периодическим изменением показателя преломления. Только длина волны излучения, которая удовлетворяет условию Брэгга для решетки, отражается обратно в резонатор лазера, что приводит к излучению лазера с крайне стабильной длиной волны. VHG-стабилизированный лазер может генерировать излучение с аналогичной шириной линии, как и DFB-лазер, но при большей мощности. При этом длина волны излучения стабильна в широком диапазоне температур и значений тока. 
Лазер объемной голографической решеткой (VHG)

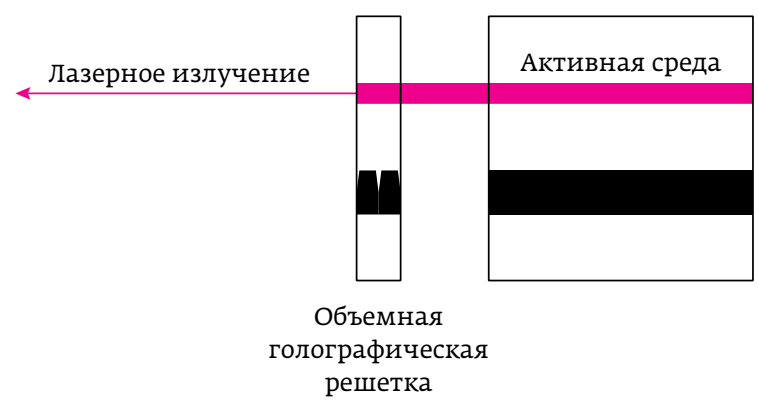

Puc. 3. Объемная голографическая решетка за предепами активной среды

\section{ЛАЗЕРЫ С РАСПРЕДЕЛЕННЫМ БРЭГГОВСКИМ ОТРАЖАТЕЛЕМ (DBR)}

Taк же, как и DFB-лазеры, лазеры с распределенным Брэгговским отражателем обладают внутренней решетчатой структурой. Однако, в отличие от DFBлазеров, где решетчатая структура расположена вдоль всей активной среды (области усиления сигнала), в DBR-лазерах такая решетка или несколько решеток расположены вне данной области (рис. 4). B целом DBR-лазер может быть оснащен несколь кими такими структурами, что не характерно для DFB-лазера и расширяет диапазон перестройки, а также позволяет осуществлять больший контроль над параметрами излучения. Например, многоэлектродный DBR-лазер может включать структуру, которая позволяет осуществлять тонкую настройку частоты генерации независимо от периода решетки и тока лазерного диода. Таким образом, DBR-лазер может работать в одночастотном режиме в широком диапазоне перестройки. DBR-лазеры с высокотехнологичной решеткой могут иметь диапазон перестройки до 30-40 нм. В отличие от излучения DFB-лазеров, выходное излучение DBR-источника не свободно от перескока мод, таким образом, температура и входные сигналы должны жестко контролироваться.

Для упрощения структуры многоэлектродного DBR-лазера был разработан DBR-лазер с одним электродом. Такой лазер не обладает сложной системой управления решеткой и частотой генерации, однако и диапазон перестройки для данных моделей уже. У данной конструкции диапазон перестройки аналогичен диапазону перестройки DFBлазера, но возможен перескок моды. Несмотря на такой недостаток, как скачки моды, DBR-лазеры с одним электродом обладают рядом преимуществ над DFB-источниками, в частности, более высокой
Лазеры с распределенным Брэгговским отражателем (DBR)

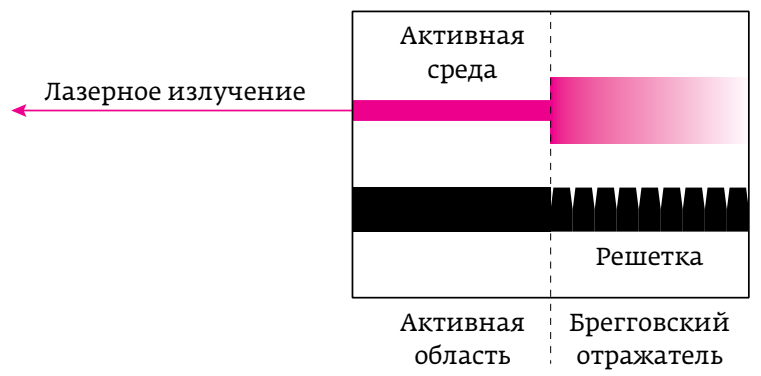

Puс. 4. Отражатель Брэгга за пределами активной среды

мощностью, так как решетка не расположена непрерывно вдоль всей длины активной области. DBR-и DFB-лазеры обладают одинаковой шириной спектральной линии.

\section{ЗАКЛЮЧЕНИЕ}

ECL-, DFB-, VHG- и DBR-лазерные диоды работают в одночастотном режиме на всем диапазоне перестройки. Лазеры с внешним резонатором (ECL) могут быть разработаны для более широкого выбора длин волн, чем DFB- или DBR-лазеры. Несмотря на модовые скачки, он также обеспечивает самую узкую ширину линии (<1 МГц) из трех представленных вариантов. Надлежащим образом разработанные компоненты ECL-лазера могут также обеспечить широкий диапазон перестройки (>100 нм).

DFB-лазер является наиболее стабильным одночастотным перестраиваемым лазером из четырех. Он может работать без перескока мод во всем диапазоне перестройки (<5 нм), что делает его одним из самых популярных форм одночастотного лазера для большей части промышленных применений. Он имеет самую низкую выходную мощность из-за присущих ему свойств непрерывной структуры решетки обратной связи.

VHG-лазер обеспечивает наиболее стабильную длину волны излучения во всем диапазоне температур и токов и может обеспечить более высокие мощности, чем типичные DFB-лазеры. Эта стабильность превосходно позволяет использовать VHG-лазеры для ОЕМ применений.

Одноэлектродный DBR-лазер обеспечивает аналогичную ширину линии и диапазон перестройки как и DFB-лазер (<5 нм). Тем не менее данный лазер имеет периодические модовые скачки в его кривой перестройки.

ООО «Компания "АЗИМУТ ФОТОНИКС", аzітр.ги 